\title{
Reflexão sobre a Inclusão da Mulher Mastectomizada a partir do Desenvolvimento de Produtos de Vestuário
}

Thinking about Inclusion of Mastectomized Women from the Development of Clothing

SILVA, Luciana; Especialista; Centro Universitário de João Pessoa

luciana.silva@unipe.br

Bastos, Victoria Fernandez; Mestre; Centro universitário de João Pessoa

vickfb@gmail.com

\section{Resumo}

O presente artigo busca refletir sobre os danos causados pelo câncer de mama, que vai muito além da questão física e analisar a autoestima da mulher mastectomizada com o objetivo de utilizar o desenvolvimento de peças do vestuário para auxiliar nessa reconstrução e adaptação coma imagem, analisando aspectos de antropometria, ergonomia, conforto e vestibilidade. Pretende-se com essa pesquisa despertar o interesse de profissionais da área, designers de moda, estudantes e afins na busca em atender as necessidades do público e preencher lacunas existentes nesse segmento. A pesquisa a ser realizada será de caráter exploratório com a finalidade de compreender as necessidades do público-alvo em questão buscando melhorias no desenvolvimento de produtos.

Palavras Chave: modelagem plana; ergonomia; mastectomia e design de moda.

\begin{abstract}
This article aims to reflect on the damage caused by breast cancer, which goes beyond the physical question and analyze the self-esteem of the mastectomized woman with the objective of using the development of garments to assist in this reconstruction and adaptation with the image, analyzing aspects of anthropometry, ergonomics, comfort and wearability. The aim of this research is to arouse the interest of professionals in the field, fashion designers, students and the like in the quest to meet the needs of the target and fill gaps in this segment. The research to be performed will be exploratory in order to understand the needs of the target public in question seeking improvements in pattern.
\end{abstract}

Keywords: pattern; ergonomics; mastectomy and fashion design. 


\section{Introdução}

É fato que o sistema da moda possui papel muito importante para a inclusão social, pois é através da moda que os indivíduos podem expressar sua identidade, seus sentimentos, seus desejos, que de certa forma, podem ser mostrados através do vestuário. Para que as pessoas possam se expressar através de suas roupas, estas devem estar adequadas ao seu biótipo, talvez, por essa razão a adaptação da roupa ao corpo seja atualmente um tema recorrente nos estudos sobre inclusão social, principalmente quando referentes a alguns públicos específicos como pessoas portadoras de deficiências ou com necessidades especiais. Ainda que trate-se de um tema que vem ganhando espaço nas discussões sobre inclusão, existe uma escassez de pesquisas e publicações relacionadas a fatores que considerem aspectos funcionais, estéticos e também ergonômicos que possam influenciar e despertar o interesse no âmbito acadêmico.

A proposta de pesquisa nasceu à partir de estudos e experiências desenvolvidas em sala de aula com discentes do curso de graduação em Design de Moda, especificamente nas disciplinas de Modelagem e Confecção de Vestuário. Para essa experiência foi proposto um desafio aos discentes, para desenvolver um projeto de modelagem inclusiva, com o objetivo de realizar um estudo sobre diferentes tipos de biótipos que não são contemplados nas tabela de medidas industriais e no padrão proposto pela indústria da moda, a partir desse estudo buscaram soluções e inovadoras para atender esse público específico. A partir da reflexão sobre a atividade vivida, surgiram diversos questionamentos: de que forma é possível criar produtos de vestuário através da perspectiva da inclusão? como contribuir com esse público carente e negligenciado pela indústria da moda?

Como objetivo central do presente trabalho visa compreender este contexto considerando as dificuldades do vestir de pessoas com necessidades especiais, onde propomos estudos e análise das necessidades existentes para esse público, através de pesquisas e estudos do corpo, ergonomia e conforto através do desenvolvimento de produtos e estudos de modelagens, moulage e prototipagens dos produtos, essa reflexão tem como base no universo que envolve as mulheres mastectomizadas.

Sabemos que a mulher mastectomizada ainda é um público ainda pouco estudado dentre os profissionais da área de moda e o câncer ou CA, como alguns preferem se referir, doença que tanto assusta e tão presente em nosso cotidiano, não é difícil pensar quantas pessoas ao nosso redor não sofrem ou sofreram deste mal, quando não nós mesmos. Partindo dos questionamentos apresentados, este artigo propõe como resultado a pesquisa, benefícios e também dificuldades relacionadas ao desenvolvimento de produtos de moda ergonomicamente adequadas voltadas para o público-alvo. A pesquisa se deu a partir de um estudo preliminar sobre o contexto em que o câncer de mama atinge as mulheres e suas consequências, considerando a moda como um possível instrumento de apoio e reintegração da mulher mastectomizada na sociedade. Para isto foi realizado uma pesquisa bibliografia e de publicações em artigos e anais de congressos da área da moda, que se apresentou bastante escasso. Posteriormente foi realizada um levantamento a respeito de projetos e marcas que tratam da temática considerando o viés da inclusão.

\section{Contexto}

Segundo o Instituto Nacional do Câncer - INCA, não se trata de uma única doença, mas de 
um conjunto de mais de 100 doenças, tendo em comum o crescimento desordenado das células que comprometem tecidos e órgãos, tendem a ser agressivos e incontroláveis formando tumores malignos espalhando-se por todo o corpo humano, de acordo com pesquisa realizadas recentemente (INCA, 2018).

Existem diversos tipos de câncer, dentre os quais os mais severos são: o câncer de pulmão que lidera a pesquisa como o que mais mata no mundo, o câncer de mama, colo de útero, próstata, cólon e reto (intestino grosso), pele, estômago, esôfago, medula óssea (leucemias) e cavidade oral (boca). A prevenção do câncer, ainda, não é possível mas existem diversos fatores que corroboram com o aparecimento da doença como o tabagismo, uso de bebidas alcoólicas e doenças ligadas ao sedentarismo e má alimentação (INCA,2018).

Neste contexto o câncer de mama é uma das doenças mais temida entre as mulheres, pois pode surgir em média à partir dos 35 anos de idade, mas após os 50 anos o aumento de casos é ainda maior. Dados apontam que esse número aqui no Brasil vem crescendo a cada ano, segundo o INCA (2018) milhares de mulheres morrem anualmente acometidas pela doença, entre os homens este tipo de câncer acomete apenas $1 \%$ do total dos casos.

O tratamento do câncer de mama varia de acordo com o tumor de cada paciente entre as formas de tratamento estão: radioterapia, quimioterapia, terapia hormonal. Levando em consideração a severidade do câncer de mama, quando não é detectado precocemente o tratamento mais comum para a doença é a Mastectomia, que é a retirada total ou parcial do tecido mamário.

Ao longo do tempo tem surgido em todo o mundo diversas campanhas que promovem a conscientização para a prevenção do Câncer de mama, uma das mais conhecidas é o Outubro Rosa nascido em Nova York nos Estados Unidos, em 1991, após uma corrida organizada pela Fundação Susan G. Komen for the cure (Corrida pela Cura) na ocasião todos os participantes receberam um laço rosa para ser colocado ao peito.

Figura 1 - Corrida pela Cura em 1991

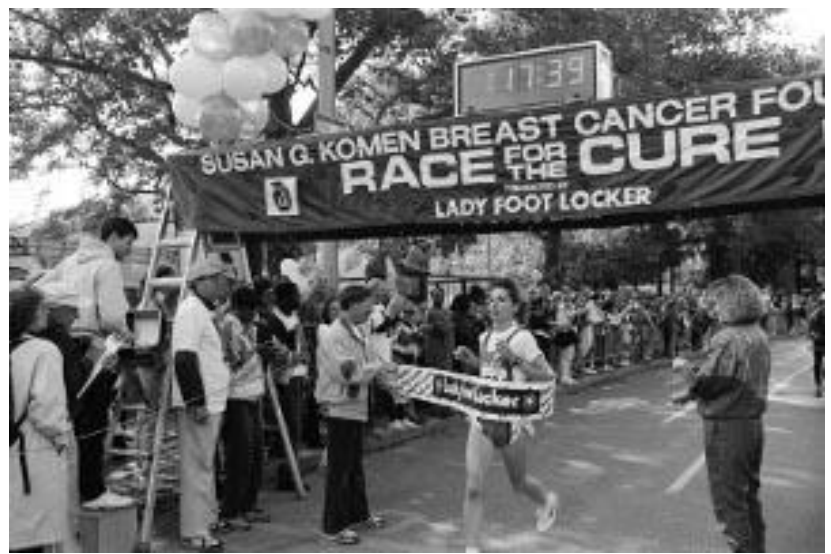

Fonte Site: http://www.gazetadopovo.com.br/viver-bem/comportamento/voce-conhece-historia-outubro-rosa/

As Campanhas do Outubro Rosa acontecem todos os anos, especificamente no mês de outubro, as ações são intensificadas visando conscientizar a população para a doença. Diversos órgãos, empresas e instituições no geral se unem pela causa e o laço rosa tem sido usado como 
símbolo da campanha.

De certo modo a moda vêm contribuído com ações voltadas para a conscientização e despertando para essa causa. Em 1994, o estilista Ralph Lauren criou uma campanha chamada Fashion Targets Breast Cancer, sensibilizado pela amiga que enfrentava o câncer mama a jornalista Nina Hyde. O estilista também foi responsável pela criação da imagem do alvo azul, a Campanha foi lançada em vários países e tem ajudado a custear despesas com o tratamento de milhares de mulheres, como também ampliação de hospitais e complexos hospitalares. Em 1995, O Instituto Brasileiro de Controle do Câncer (IBCC), firmou parcerias com alguns Designers de moda, estilistas renomados e empresas no Brasil, a campanha O Câncer no Alvo da Moda, invadiu as passarelas dos principais desfiles de moda e trouxe um olhar diferenciado para a doença. A camiseta com o alvo azul foi o estandarte da campanha e usada por celebridades e artistas, o símbolo foi utilizado em produtos dos diversos segmentos da moda.

Figura 2 - O Câncer no Alvo da Moda

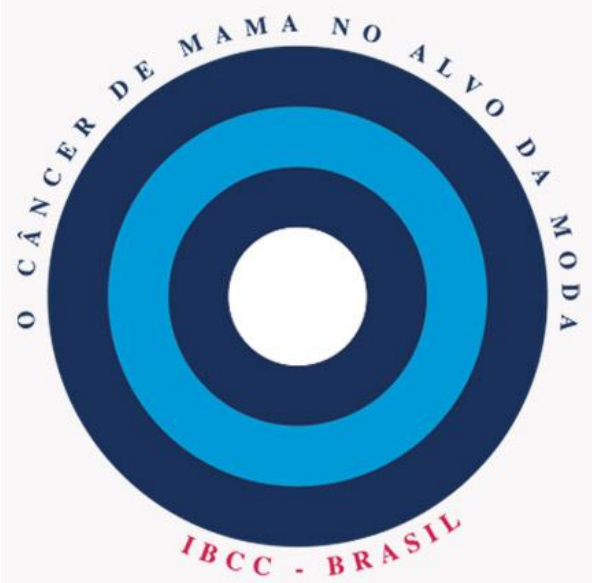

Fonte: IBCC (2014).

O objetivo desse trabalho é auxiliar, principalmente, profissionais da área de moda, designers, estilistas e estudantes para o desenvolvimento de peças de vestuário que auxiliem as mulheres que tanto sofreram com o processo da mastectomia, buscando especificamente no desenvolvimento de produtos e especificamente na modelagem plana uma solução ergonômica, propondo conforto e vestibililidade, com qualidade, elegância, personalidade, levando em consideração a necessidade de recuperar a autoestima da mulher mastectomizada para que se encontre novamente, também, no vestir.

\section{Mastectomia, Autoestima e Moda}

A mastectomia foi o primeiro procedimento médico capaz de curar o câncer, pois consiste em um procedimento, bastante invasivo, de retirada da mama impedindo que o tumor se espalhe para outros órgãos do corpo e continue se desenvolvendo. De acordo com Azevedo (2004), existem três tipos de procedimentos cirúrgicos para o tratamento do câncer de mama: (i) mastectomia parcial, que preserva parte da mama; (ii) mastectomia unilateral, que consiste na retirada apenas da mama onde foi localizado o tumor e (iii) dupla mastectomia, quando ambas as mamas são 
retiradas.

É muito natural que após a cirurgia da mastectomia a mulher experimente as alterações em sua imagem devido à ausência da mama e desencadeie na perda da feminilidade e a baixa da autoestima, nesse período do tratamento. Na tentativa de reduzir essas frustrações e sensação de mutilação muitas mulheres optam pela reconstrução cirúrgica da mama (SARIAN, 2010). De acordo com Sarian (2010), no Brasil, as técnicas mais comuns são: a reconstrução com o retalho do músculo reto abdominal, com o retalho de músculo grade dorsal e a utilização de um expansor, que, posteriormente é substituído por uma prótese de silicone. Segundo o mastologista Costa (2013), existem outras técnicas para realizar a reconstrução da mama, mas cada situação deve ser levada em consideração, ainda, justifica que algumas reconstruções não poderão ser realizadas devido a agressividade do câncer.

Em 24 de Abril de 2013, as mulheres ganharam reforço quando a presidente da República, no período, Dilma Rousseff, sancionou a Lei 12.802/2013 que obriga o Sistema Único de Saúde - SUS a fazer a cirurgia plástica reparadora da mama logo em seguida à retirada do câncer, quando houver condições médicas. A lei anterior (Lei 9.797/1999) já previa que mulheres que sofressem mutilação total ou parcial de mama (mastectomia) teriam direito à cirurgia plástica reconstrutiva, porém sem especificar o prazo em que ela deveria ser feita.

Quando se trata de autoestima a primeira coisa a que nos remete são questões como beleza e vaidade, no entanto pode-se definir autoestima de acordo com Langone e Vieira $(2009$, p.3) no artigo "Autoestima: Atualização do conceito da Abordagem Centrada na Pessoa", definem autoestima como sendo:

(...) a capacidade de consideração para com o próprio Eu coma Unidade. É percepção de potencialmente ser capaz, feliz, a pessoa do, sentindo e percebendo valores de dentro para fora. É acreditar em si como potencial de vir a ter e ser, tendo ideais: de vida, de prosperar, de ter dignidade, caráter, confiança e dinamismo, acreditando em si e no outro; de interagir e integrar, integrando (LANGONE E VIEIRA, 2009, p.3).

A autoestima da mulher mastectomizada é algo que merece acompanhamento e atenção durante todo o tratamento, devido a fragilidade e as circunstâncias pela qual a mulher se encontra. Mastectomizada a mulher experimenta o sentimento de ser uma pessoa incompleta, marginalizada, nesse momento, os acontecimentos ao longo da sua vida influenciam positiva ou negativamente na aceitação da nova imagem (ARAúJO,2010).

A relação da mulher com a sua imagem acaba se refletindo na moda e com o vestir. A perda da mama faz com que a mulher sinta dificuldade em expressar sua intimidade, a exemplo disso, evitando praticar esportes ou atividades que envolvam roupas leve que evidenciem as formas do corpo, criando uma barreira no momento de selecionar suas roupas. Como as mulheres mastectomizadas deparam-se com mudanças na sua imagem corporal, torna-se necessário questionar essas alterações e como as mulheres se adaptam à nova identidade.

Durante a pesquisa inicial foi possível identificar a existência de projetos e marcas voltadas especificamente para mulheres mastectomizadas. Nesse âmbito podemos destacar o trabalho do fotógrafo de moda David Jay criou um projeto chamado de The Scar Project (Projeto Cicatriz), que retrata a realidade de mulheres sobreviventes ao câncer de mama, suas fotografias já foram expostas no Museu de Arte Contemporânea do Rio de Janeiro em 2014, a convite da Fundação Pink Ribbons, Niterói Mais Humana. 
Figura 3 - The Scar Project
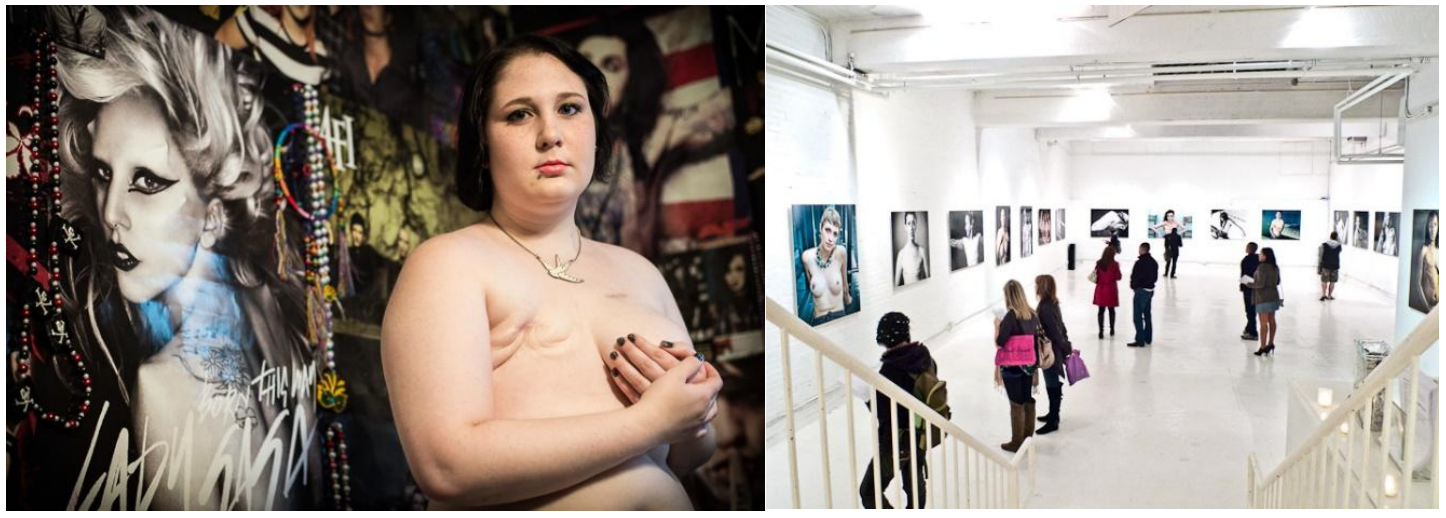

Fonte Site: www.thescarproject.org

Com a mesma perspectiva o Projeto Monokini 2.0 que desenvolveu peças de roupas de banho para mulheres mastectomizadas. O objetivo do projeto segundo os líderes criativos Katriina Haikala e Vilma Metteri, era expandir a ideia da cultura comercial do que é considerado belo na aparência e no corpo da mulher, enfatizando a autoestima da mulher. A coleção Swimear foi desenvolvida por um grupo de estilistas finlandesas e modeladas por mulheres que passaram por diversos tipos de mastectomia, a ideia original foi da Elina Halttunen uma mulher que passou pela cirurgia e retirada de uma das mamas, como pode ser visto nas imagens a idealizadora do projeto Elina Halttunen vestindo um dos looks da coleção, além da idealizadora do projeto outras mulheres mastectomizadas se colocaram como voluntárias e pousaram para fotos usando as peças.

Figura 4 - Monokini 2.0

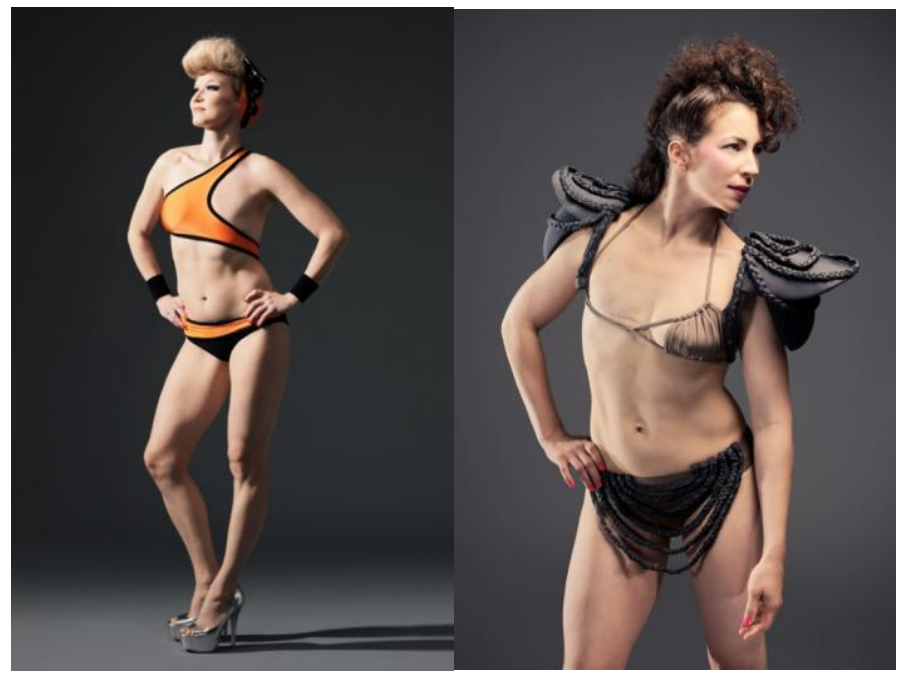

Fonte site: www.monokini2.com

Uma das marcas estudada foi a Mama Amiga, possui uma loja que funciona desde 1985 no bairro dos Pinheiros em São Paulo, sendo uma das pioneiras no segmento destinados a desenvolver produtos de moda para a mulher mastectomizada. 
Figura 5 - Mama Amiga

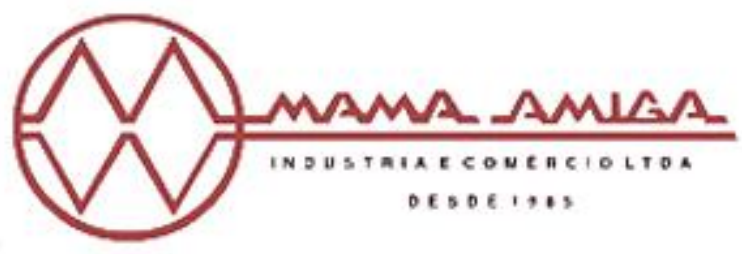

Fonte: www.mamaamiga.com.br (2018)

A loja surgiu depois que a proprietária Miryan Sanchez, aos 31 anos teve que passar por diversos procedimentos e a retirada de uma das mamas, segundo a empresária a dificuldade em encontrar produtos específicos era tanta que surgiu a ideia de investir no ramo "as peças íntimas que encontrava eram tudo sem graça e com cara de cirurgia" (SANCHEZ, 2013). A missão da loja é oferecer produtos que prezem pelo conforto, com sutiãs forrados para acomodação da prótese, maiôs e biquínis com modelagem especial, mais fechados no decote, na cava e debaixo do braço para a cicatriz não ficar em evidência.

(...)tudo para que a mulher fique completamente satisfeita e não se sinta diferente do resto do mundo (...). Nosso trabalho, acima de tudo, é não permitir que a mulher se limite a um sutiã sem graça, bege. É muito desagradável a pessoa passar por um problema de saúde tão sério e ainda ser impedida de vestir o que deseja (...)Continuar com a autoestima lá em cima e ter a oportunidade de escolher o que usar faz toda a diferença (SANCHEZ,2013).

Considerando as alterações sofridas no corpo, mesmo tendo seios em tamanhos diferentes, ou até mesmo não os tendo, a busca pelo conforto e vestibilidade em peças de roupas que auxiliem ou solucionem essas diferenças são prioridade. Ao pesquisar o público de mulheres mastectomizadas percebe-se a diferenças de medidas do busto e alterações provenientes da cirurgia, sendo assim acredita-se que a modelagem de produtos de vestuário para este público necessite ser desenvolvido com o devido cuidado e atenção, para apresentar propostas adequadas, algumas possibilidades para diminuir essas diferenças podem ser propostas como volumes como uso de pregas, franzidos e drapeados, ou mesmo recortes diferenciados que evidenciem o busto menor.

\section{Considerações Finais}

Como relatado ao longo deste trabalho, é possível perceber que as consequências da mastectomia na vida da mulher são devastadoras, acarretando em vários tipos de enfrentamentos que variam dependendo do contexto em que a mesma está inserida. É evidente que a experiência da mastectomia é ampla e distinta para cada mulher, envolvendo implicações na vida diária, além das relações entre ela e as pessoas do seu convívio.

Tendo como motivação minimizar o sofrimento e auxiliar na aceitação da nova imagem, a pesquisa de modelagens adequadas para mulheres mastectomizadas torna-se bastante relevante. Verificou-se que não existe uma bibliografia especifica sobre o assunto, assim como as publicações na área de design e moda, especificamente, são muito insipientes. Sendo assim visamos com este trabalho e a pesquisa desenvolvida, despertar o interesse de designers de moda, modelistas, empresas e a comunidade acadêmica de forma a atender as necessidades do público e preencher 
as lacunas existentes nesse segmento, tendo em vista a inclusão como peça chave do processo de criação e confecção de vestuário.

Acredita-se que as peças de roupas desenvolvidas após a análise das necessidades e possibilidades ergonômicas do público-alvo estudado permitirá que produtos diferenciados sejam desenvolvidos com foco na modelagem, pois entende-se que para corpos diferenciados, além de aplicações de técnicas de modelagem, devem ser aplicadas variações que acompanhem as alterações às quais o corpo se expõe. Tendo em vista que a modelagem do produto é de extrema importância e relevância, principalmente, quando se refere a um público com características tão especificas a serem estudadas e analisadas durante o desenvolvimento do produto. A proposta de continuidade da pesquisa é analisar os diferentes biótipos da mulher mastectomizada, considerando os aspectos ergonômicos de conforto e vestibilidade e transferir esses estudos ao desenvolvimento de produtos de moda com a finalidade de adequação e composições de looks que tragam linguagem de moda.

Assim como foi visto na experiência realizada com o grupo de alunos do curso de Design de Moda é importante salientar o surgimento do interesse destes pela temática de inclusão social, onde foi possível enxergar notoriamente o engajamento e a satisfação de solucionar e refletir sobre o assunto, pois tiveram a oportunidade de dar sua contribuição e trazer soluções para produtos com o olhar mais humano para a inclusão social. Visto que para entender e descobrir os problemas presentes no dia a dia de uma pessoa com necessidades especiais, foi necessário realizar uma pesquisa bibliográfica e de campo, utilizando a ferramenta da entrevista com o público para a coleta de dados. Os projetos realizados e os dados analisados foram apresentados em sala de aula, com todas as etapas do processo, desde a pesquisa, análise dos resultados e construção do produto final.

As reflexões abordadas nesse artigo trazem à tona uma problemática existente visando necessidade de aprofundamento e pesquisa não só apenas no âmbito acadêmico, mas em todas as esferas da sociedade através de políticas públicas sociais. A inclusão social no Brasil vem caminhando e ganhando espaço de forma lenta e isso é fator relevante para destacarmos e chamar a atenção para essa classe de pessoas ainda não incluídas na sociedade, principalmente no que tange a moda. Vale ressaltar que a inclusão definitiva da pessoa com algum tipo de deficiência depende de um conjunto de ações, e para que isso ocorra é preciso garantir alguns aspectos para que a pessoa se sinta de fato integrada à sociedade. Sabemos que o designer, estudantes e profissionais da área tem muito a contribuir, pois trazem consigo a capacidade de propor soluções e trazer posicionamentos pertinentes e capazes de suprir e atender as necessidades de um público específico, seja por meio da moda ou por qualquer outro aspecto.

Assim, esse artigo busca mostrar para a sociedade acadêmica que podemos fazer a diferença e termos responsabilidade acerca do assunto abordado e propor ao designer resoluções e soluções acerca da inclusão social diminuindo as lacunas existentes nesse segmento. Através de estudos podem surgir matérias-primas específicas, modelagens desenvolvidas com base na ergonomia respeitando as limitações corpóreas, valorizando a autoestima da pessoa com necessidades especiais e diversos produtos que podem solucionar o problema em questão.

Despertar esse olhar requer sensibilidade e mais do que isso, se colocar no lugar do outro. Que outros pesquisadores e profissionais possam continuar essa pesquisa ampliando ainda mais os horizontes para temas como este que tanto necessitam da nossa atenção. 


\section{Referências}

ARAÚJO, M. Tecnologia do vestuário. Lisboa: Fundação Calouste Gulbenkian, 1996.

AZEVEDO, D. R. e BARROS, M. C. M. e MULLER, M. C. Organizadores. Psicooncologia e interdisciplinaridade: Uma experiência na educação a distância. Porto alegre: EPICURS, 2004.

GERNREICH, Rudi. The Designer of the original Monokini 1964. (http://www.monokini2.com/whoare-they/)

$\begin{array}{lllllll}\text { INSTITUTO BRASILEIRO } & \text { DE } & \text { CONTROLE } & \text { DO } & \text { CÂNCER. } & 2016 .\end{array}$ (http://www.ibcc.org.br/SitelbccCampanha/ibcc.asp)

INSTITUTO NACIONAL DO CÂNCER. Mama.

(http://www2.inca.gov.br/wps/wcm/connect/tiposdecancer/site/home/mama)

JAY, D. The Scar Project. In: The Sacar project, 2011. (http://www.thescarproject.org/)

LANGONE, A. e VIEIRA, N. Autoestima: atualização do conceito da Abordagem Centrada na Pessoa. 2009. (http://www.encontroacp.psc.br/ autoestima.htm)

PAGANINE. J. Lei garante reconstrução da mama em seguida à retirada de câncer, 2013. (https://www12.senado.leg.br/noticias/materias/2013/05/07/lei-garante-reconstrucao-da-mamaem-seguida-a-retirada-de-cancer)

REDAÇÃO, Viver Bem. In: Comportamento, Gazeta do Povo, 2014. (http://www.gazetadopovo.com.br/viver-bem/comportamento/voce-conhece-historia-outubrorosa/)

SABRÁ, F. Modelagem: Tecnologia em produção de vestuário. São Paulo: Estação das Letras e Cores, 2009.

SARAM, L. Sutiã para mastectomizadas: empresária desenvolve peças especiais para mulheres com câncer de mama, 2013. (http://revistamarieclaire.globo.com/Mulheres-doMundo/noticia/2013/11/sutia-para-mastectomizadas-empresaria-desenvolve-pecas-especiaispara-mulheres-com-cancer-de-mama.html) 